\title{
Morphological Characterization and Diversity of T. Aman Rice Germplasm of Bangladesh
}

\author{
M S Ahmed*, E S M H Rashid, N Akter and M Khalequzzaman
}

\begin{abstract}
Fifty-four T. Aman rice landraces were studied for 11 morphological and yield contributing characters at Bangladesh Rice Research Institute during T. Aman 2016 season. The largest variation was observed for yield per hill with $53.6 \% \mathrm{CV}$, followed by 1000 grain weight (29.9), number of effective tillers per hill (22.8), culm diameter (18.8), leaf width (18.4), leaf length (18.1) and days to maturity (6.7) respectively. The longest leaf was recorded as $82.2 \mathrm{~cm}$ and that of culm diameter as 7.57 $\mathrm{mm}$, grain length as $7.2 \mathrm{~mm}$ and LB ratio as 3.48. The shortest days to maturity (110 days) was observed in Kajal lata and plant height $(86.6 \mathrm{~cm})$ in Haijam. Indursail possessed the longest panicle $(31.6 \mathrm{~cm})$ and the highest yield per hill $(24.3 \mathrm{~g})$. Based on $\mathrm{D}^{2}$ values, all the germplasm were grouped into 15 clusters using Mahalonobis $\mathrm{D}^{2}$ statistic. The maximum numbers of germplasm (7) were grouped into the clusters IV with VI, whereas clusters III and XIII contained the minimum (1). The highest intra-cluster distance (1.0) was found in cluster II and the lowest (0.0) in clusters III and XIII, respectively. The inter-cluster $\mathrm{D}^{2}$ values ranged from 19.2 to 0.6 indicating wide range of diversity among the germplasm. Cluster XIII showed the highest leaf length $(82.2 \mathrm{~cm})$ and culm diameter $(6.5$ $\mathrm{mm}$ ), cluster IX the highest effective tillers per hill (13), cluster II the lowest days to maturity (117), cluster XV the highest grain length $(6.1 \mathrm{~mm})$ and cluster I the highest grain LB ratio (2.97), while cluster VIII showed the highest yield per hill $(22.0 \mathrm{~g})$, panicle length $(28.8 \mathrm{~cm})$ and 1000 grain weight (25.2 g), respectively. Finally, the germplasm under clusters VIII may be selected for crossing with the germplasm from clusters XIII, IX, II, XV and I for developing high yielding varieties with improved panicle length, effective tillers per hill, growth duration and grain type.
\end{abstract}

Key word: Morphology, genetic diversity, T. Aman, germplasm, Bangladesh

\section{INTRODUCTION}

Rice (Oryza sativa L.) is the staple food of Bangladesh, as well as the half of the world's population. Rice is also a commodity of significance and the easiest food source in Bangladesh. The availability and its price are also a major determinant of the welfare of the least food-secure segment of the country. However, with an increasing global population, the demand for rice will continue to rise, which raises challenges for the breeding of high yielding rice cultivars (Zhang et al., 2013).

Rice production at farmer's level is increasing day to day in Bangladesh due to the constant development of many promising varieties for different rice ecosystems. Consequently, this bridge between technology and farmer now make Bangladesh possible to achieve the self-sufficiency in food grain production.

Genetic diversity created in the farmers' fields over millennia, complemented by the diversity present in wild relatives of crops, provides the primary material for improving crop productivity through plant breeding (Upadhyaya et al., 2008). The amount of genetic enrichment is reliant on the extent of genetic diversity inherent in a population (Kumbhar et al., 2015). A reduction in germplasm diversity is an obstacle to plant breeding and reduce the tendency of plants to resist unfavourable environments (Xiyong et al., 2012). Landraces of rice can contain some valuable alleles not common in modern germplasm (Pervaiz et al., 2010). 
Genetic variation in plant material is the base for crop improvement (Iqbal et al., 2014). Any crop improvement programme depends on the utilization of germplasm. Evaluation and characterization of existing landraces of rice are important due to increasing needs of varietal improvement. The pool of genetic variation within a population is the basis for selection as well as for plant improvement. Before exploiting a population for trait improvement, it is necessary to understand the magnitude of variability in the population which is fundamental for genetic improvement in all crop species. Agro-morphological characterization of germplasm accessions is fundamental criteria in order to provide information of plants (Lin, 1991) for plant breeding programmes (Das and Ghosh, 2011). Agro-morphological traits, both qualitative and quantitative have been commonly and traditionally used to estimate relationships between genotypes (Goodman, 1972). Finally, Lahkar and Tanti (2017) studied the morphological variation of 22 aromatic rice landraces of Assam using five qualitative and seven quantitative traits and reported that in rice improvement programme characterization of landraces could help breeders to utilize appropriate characters. Though a number of transplanted Aman rice germplasm have existed in different agro-climatic conditions of Bangladesh but their characterization is not sufficient. Therefore, the objectives of the present study was to characterize using morphological traits of the local transplanted Aman rice germplasm of Bangladesh for providing useful informations in rice breeding programmes.

\section{MATERIALS AND METHOD}

Fifty-four newly collected rice landraces from BRRI Genebank were studied for genetic diversity through morphological characterization (Table 1). The experiment was conducted using a single row of $5.4 \mathrm{~m}$ long for each entry with a spacing of $25 \times 20 \mathrm{~cm}$ between rows and plants respectively during T. Aman 2016 season at Genetic Resources and Seed Division, BRRI, Gazipur. The thirty-fiveday-old single seedling was transplanted in randomized complete block design (RCBD) with three replications. All the fertilizers except $\mathrm{N}$ were applied @ 60:20:40:12 kg NPKS/ha at final land preparation. All fertilizers were applied in basal, except urea. Intercultural operations and pest control measures were taken as and when necessary.

Data were collected on leaf length $(\mathrm{cm})$, leaf width $(\mathrm{mm})$, culm diameter $(\mathrm{mm})$, effective tillers per hill, panicle length $(\mathrm{cm})$, plant height $(\mathrm{cm})$, days to maturity (days), grain length $(\mathrm{mm})$, grain LB ratio, 1000 grain weight (TGW) and yield per hill (g). Simple statistics (means, ranges etc.) was calculated to have an idea of the level of variation. The genetic diversity was studied following Rao (1952), which was originally developed by the generalized distance $\left(\mathrm{D}^{2}\right)$ as proposed by Mahalonobis (1936). The germplasm were grouped into clusters using canonical vector analysis. All the statistical analysis regarding diversity was carried out using the GENSTAT 5.5 software.

\section{RESULTS AND DISCUSSION}

Morphological characterization. Analysis of variance revealed that the 54 germplasm showed highly significant differences for all the 11 studied morphological characters. Table 2 presents the details of the characterization results. The largest variation was observed for yield per hill with $53.6 \% \mathrm{CV}$, followed by TGW (29.9), number of effective tillers per hill (22.8), culm diameter (18.8), leaf width (18.4), leaf length (18.1) and the smallest in days to maturity (6.7) respectively. 
Table 1. List of rice germplasm characterized during T. Aman 2016.

\begin{tabular}{|c|c|c|c|c|c|c|c|}
\hline Variety & Code* $^{*}$ & Upazila & District & Variety & Code* $^{*}$ & Upazila & District \\
\hline Double rice & TA1 & Kaliganj & Jhenaidah & Molla digha & TA28 & Shibalaya & Manikganj \\
\hline Tulshi mala & TA2 & Fulpur & Mymensingh & Modhu sail & TA29 & Shibalaya & Manikganj \\
\hline Kajal lata & TA3 & Jhikorgacha & Jashore & Indursail & TA30 & Ulipur & Kurigram \\
\hline Subal lata & TA4 & Jhikorgacha & Jashore & Jira bhog & TA31 & Vurangamari & Kurigram \\
\hline $\begin{array}{l}\text { Hb. Aman II } \\
\text { (Lacki) }\end{array}$ & TA5 & BRRI & Habiganj & Malshira & TA32 & Vurangamari & Kurigram \\
\hline Depor dhan & TA6 & Nagarpur & Tangail & Khirshapal & TA33 & Ulipur & Kurigram \\
\hline Kalo parangi & TA7 & Nagarpur & Tangail & Dudh kolom & TA34 & Ulipur & Kurigram \\
\hline Swarna & TA8 & Nagarpur & Tangail & Narikel jhupi & TA35 & Ulipur & Kurigram \\
\hline Lalsaina & TA9 & Nagarpur & Tangail & Urichadra & TA36 & Ovainagar & Jashore \\
\hline Jotalaijum & TA10 & Nagarpur & Tangail & Ranga gasa & TA37 & Ovainagar & Jashore \\
\hline Dolni & TA11 & Ghatail & Tangail & Sada gosa & TA38 & Ovainagar & Jashore \\
\hline Barai dhan & TA12 & Ghatail & Tangail & Haringa digha & TA39 & Mirzapur & Tangail \\
\hline Chini sugar & TA13 & Ghatail & Tangail & Bagraj & TA40 & Kalihati & Tangail \\
\hline Kalijira & TA14 & Ghatail & Tangail & Begun bichi & TA41 & Sadar & Tangail \\
\hline Kiron mala & TA15 & Ghatail & Tangail & Chamara (Lal) & TA42 & Sadar & Tangail \\
\hline Apsaya & TA16 & Ghatail & Tangail & Kalijira & TA43 & Sadar & Tangail \\
\hline Chini kutei & TA17 & Ghatail & Tangail & Patjak & TA44 & Sadar & Tangail \\
\hline Biropa & TA18 & Sakhipur & Tangail & Nizersail & TA45 & Sadar & Tangail \\
\hline Gobra sail & TA19 & Sakhipur & Tangail & Dulai & TA46 & Sadar & Tangail \\
\hline Gonokrai & TA20 & Basail & Tangail & Haijam & TA47 & Sadar & Tangail \\
\hline Soma baila & TA21 & Basail & Tangail & Digha & TA48 & Sadar & Tangail \\
\hline Dulai boron & TA22 & Basail & Tangail & Aloi & TA49 & Sadar & Tangail \\
\hline Hari dhan & TA23 & Basail & Tangail & Vaeulu & TA50 & Nagarpur & Tangail \\
\hline Kartikjul & TA24 & Basail & Tangail & Heringa digha & TA51 & Nagarpur & Tangail \\
\hline Komkamane & TA25 & Sakhipur & Tangail & Hejal digha & TA52 & Nagarpur & Tangail \\
\hline Ganokairot & TA26 & Sakhipur & Tangail & Harharia & TA53 & Nagarpur & Tangail \\
\hline Bela digha & TA27 & Shibalaya & Manikganj & Sada vara & TA54 & Nagarpur & Tangail \\
\hline
\end{tabular}

*New collection.

On the other hand, 26 germplasm possessed intermediate (6-10), 27 possessed many $(>10)$ and one had few $(<6)$ number of effective tillers (Table 2). One germplasm was found with very long $(>30 \mathrm{~cm}), 11$ with long (26-30), 38 with medium (21-25) and four had short $(\leq 20)$ panicle length. Three germplasm were found with short $(<110 \mathrm{~cm}), 11$ with moderate (110-130) and 40 with long (>130) plant height. Thirteen germplasm had short (<120 days), seven had medium (120-130) and 34 had long (>130) days to maturity. Besides, 20 germplasm were found with short $(<5.6$ $\mathrm{mm}), 33$ with medium (5.6-6.5) and one with long (6.6-7.5) types of grain. Rice grain can also be classified as extra-long, long, medium and short (Bisne et al., 2006). Considering lengthbreadth ratio, 12 germplasm were found with bold (1.5-2.0), 34 with medium (2.1-2.5) and four each with medium slender (2.6-3.0) and slender (>3.0) grain. TGW of 14 germplasm was found very low (<16 g), 10 with low (1619), 19 with medium (20-23), eight with high (24-27) and three had very high (>27). Eleven germplasm possessed low $(<5 \mathrm{~g}), 26 \mathrm{had}$ moderate (5-10) and 17 had higher $(>10)$ yields per hill. Maji and Shaibu (2012) reported a wider range $(70-184 \mathrm{~cm})$ of variation with a mean value of $151.15 \mathrm{~cm}$ in plant height. Plant height in rice is a complex character and is the 
end product of several genetically controlled factors called internodes (Sarawgi and Rastogi, 2000). Reduction in plant height may improve their resistance to lodging and reduce substantial yield losses associated with this trait (Pachauri et al., 2017a). Pachauri et al. (2017b) studied 124 rice germplasm accessions on the basis of 19 morphological characters and reported that a great variability with high range (5-26) and mean of 8.20 was exhibited for number of productive tillers per plant, while high range (86-130 days) with mean of 111.33 days for days to maturity.

However, the shortest growth duration (110 days) was observed in Kajal lata and the longest (143) in Ranga and Sada gasa in the present study. The shortest plant height (86.6 $\mathrm{cm})$ was observed in Haijam and the longest (168) in Gobra sail. Indursail possessed the longest panicle $(31.6 \mathrm{~cm})$. Malshira was found with the highest number of effective tillers (18) and Harharia with the lowest (2). The highest grain length-breadth ratio (3.48) was observed in Subal lata and the lowest (1.89) in Vaeulu and Depor dhan. Komkamane had the lowest $(8 \mathrm{~g})$ and the Molla digha had the highest (31.2) TGW. The highest yield per hill (24.26 g) was observed in Indursail and the lowest (2.48) in Biropa. Table 3 presents the top ranking accessions for yield ancillary traits in T. Aman 2016. Abarshahr et al. (2011) also found valuable and highly significant and positive variability among their studied rice genotypes. Besides, Sajid et al. (2015) also reported that characterization of rice germplasm through different morphological traits is an important step for assessment of its genetic potential.

Principal component analysis. The first four components in principal component analysis with eigen values $>1$, contributed $68.78 \%$ of the total variation among the 54 germplasm for 11 morphological characters (Table 4). Chakravorty et al. (2013) also observed the contribution of $75.9 \%$ of the first four components to the total variation in rice.

Cluster analysis. Based on $\mathrm{D}^{2}$ values, the germplasm were grouped into 15 clusters using Mahalonobis $\mathrm{D}^{2}$ statistic (Table 5). Mahalingam et al. (2012) also observed 13 clusters in 31 Indian and exotics germplasm lines. Maximum numbers of germplasm (7) were grouped into the clusters IV and VII, followed by 6 in clusters V and II, 5 in cluster IX. However, clusters III and XIII contained the lowest (1) number of germplasm. The result revealed that all the germplasm collected from Tangail or Kurigram district were not clubbed into the same cluster. This pattern of clustering indicated that there was no association between the geographical distribution of genotypes and genetic divergence. The similar result was also reported earlier by Chandra et al. (2007). Considering this, Hasan et al. (2000) suggested that parents should be selected on the basis of genetic diversity rather than geographic diversity.

Table 6 indicates the variations among the intra and inter cluster distances. All the intercluster distances were larger than the intracluster distance indicating the homogeneous nature of the germplasm within the cluster. The highest intra-cluster distance was recorded for cluster II (1.00), followed by cluster I (0.83) and cluster XII (0.81) indicated the high genetic diversity among the germplasm belonging to the respective cluster. The germplasm belonging to the highest intracluster distance (cluster II) were the most heterogeneous and might develop the highest segregants by crossing between them. Again, there were marked variations in intra-cluster 


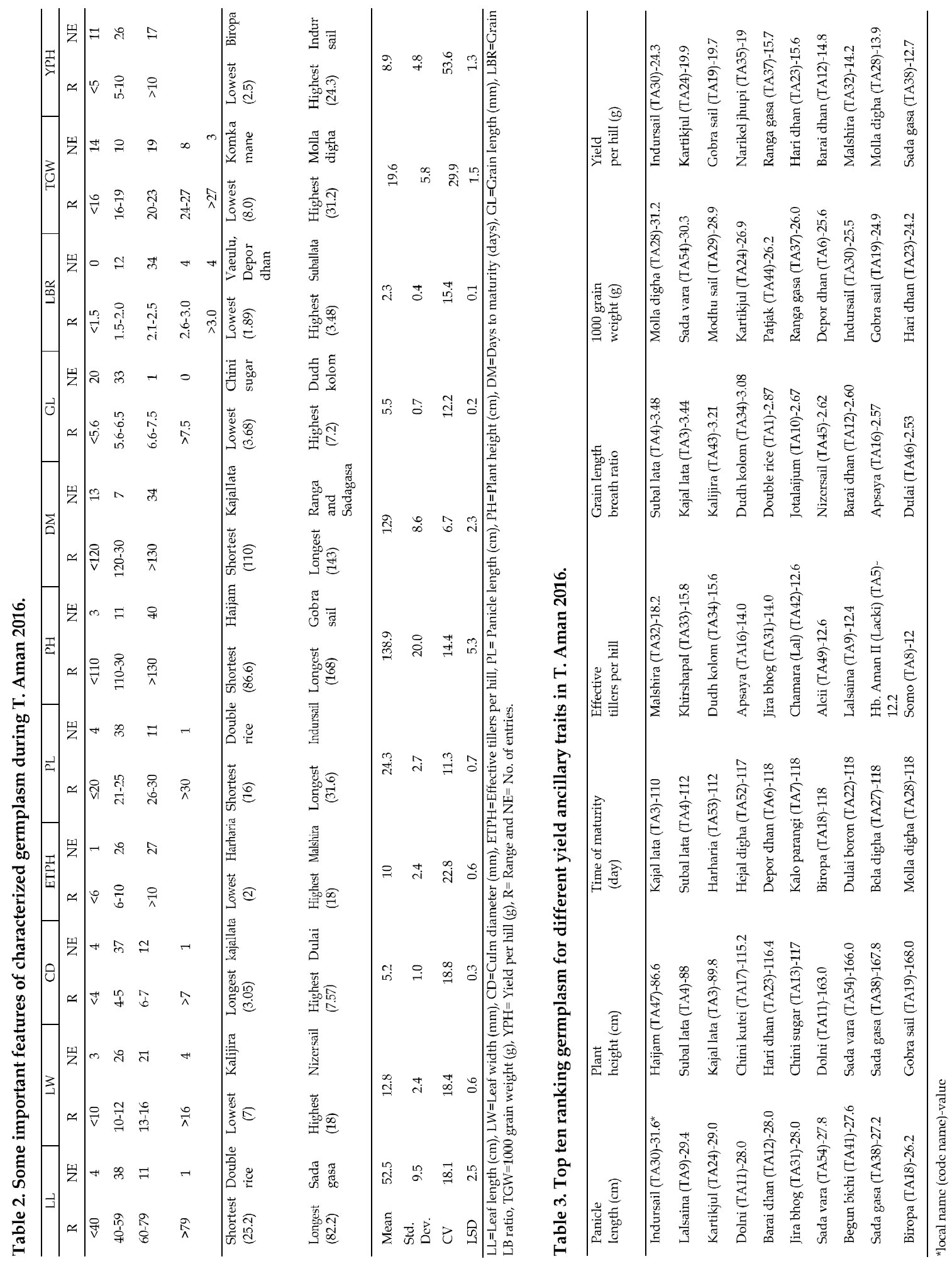


Table 4. Latent roots (eigen value) and their variation for 11 morphological characters of $54 \mathrm{~T}$. Aman rice germplasm.

\begin{tabular}{cccc}
\hline Principal Component & Latent roots & Variation accounted (\%) & Cumulative Variation (\%) \\
\hline I & 2.83 & 25.75 & 25.75 \\
II & 2.22 & 20.21 & 45.96 \\
III & 1.49 & 13.55 & 59.51 \\
IV & 1.02 & 9.27 & 68.78 \\
V & 0.91 & 8.27 & 77.05 \\
VI & 0.62 & 5.64 & 82.69 \\
VII & 0.58 & 5.25 & 87.94 \\
VIII & 0.54 & 4.9 & 92.84 \\
IX & 0.46 & 4.18 & 97.02 \\
X & 0.27 & 2.46 & 99.48 \\
XI & 0.06 & 0.53 & 100.01 \\
\hline
\end{tabular}

Table 5. Distribution of $54 \mathrm{~T}$. Aman rice germplasm into 15 clusters for 11 morphological characters.

\begin{tabular}{c|c|l}
\hline Cluster & No. of germplasm & \multicolumn{1}{c}{ Code name of the germplasm } \\
\hline I & 3 & TA3, TA4, TA47 \\
II & 6 & TA18, TA21, TA22, TA27, TA28, TA53 \\
III & 1 & TA15 \\
IV & 7 & TA2, TA12, TA14, TA16, TA31, TA41, TA43 \\
V & 6 & TA6, TA20, TA24, TA42, TA45, TA54 \\
VI & 7 & TA5, TA7, TA26, TA48, TA50, TA51, TA52 \\
VII & 2 & TA1, TA36 \\
VIII & 2 & TA19, TA30 \\
IX & 5 & TA13, TA17, TA25, TA32, TA33 \\
X & 3 & TA10, TA35, TA46 \\
XI & 3 & TA9, TA44, TA49 \\
XII & 2 & TA11, TA40 \\
XIII & 1 & TA38 \\
XIV & 2 & TA23, TA37 \\
XV & 4 & TA8, TA29, TA34, TA39 \\
\hline
\end{tabular}

Table 6. Average intra-(bold) and inter-cluster distances $\left(D^{2}\right)$ for 11 morphological characters of $54 \mathrm{~T}$. Aman rice germplasm.

\begin{tabular}{c|ccccccc|c|c|c|c|c|c|c|c|c}
\hline Cluster & I & II & III & IV & V & VI & VII & VIII & IX & X & XI & XII & XIII & XIV & XV \\
\hline I & $\mathbf{0 . 8 3}$ & & & & & & & & & & & & & \\
II & 9.9 & $\mathbf{1 . 0}$ & & & & & & & & & & & & \\
III & 12.5 & 8.3 & $\mathbf{0 . 0}$ & & & & & & & & & & & \\
IV & 11.4 & 7.1 & 1.3 & $\mathbf{0 . 6 8}$ & & & & & & & & & & \\
V & 14.4 & 5.0 & 7.5 & 6.9 & $\mathbf{0 . 7 1}$ & & & & & & & & & \\
VI & 10.7 & 1.0 & 7.9 & 6.7 & 4.0 & $\mathbf{0 . 5 7}$ & & & & & & & & \\
VII & 7.0 & 4.7 & 6.1 & 4.8 & 7.9 & 5.1 & $\mathbf{0 . 6 4}$ & & & & & & & \\
VIII & 18.3 & 9.4 & 8.3 & 8.3 & 4.6 & 8.5 & 11.3 & $\mathbf{0 . 3 9}$ & & & & & & \\
IX & 7.3 & 8.1 & 5.6 & 4.8 & 10.4 & 8.3 & 3.4 & 12.9 & $\mathbf{0 . 7 4}$ & & & & & \\
X & 9.8 & 4.3 & 4.2 & 2.9 & 5.5 & 4.0 & 2.8 & 8.6 & 4.9 & $\mathbf{0 . 7 5}$ & & & & \\
XI & 13.4 & 5.5 & 4.6 & 4.1 & 2.9 & 4.7 & 6.4 & 4.9 & 8.2 & 3.6 & $\mathbf{0 . 5 7}$ & & & \\
XII & 19.1 & 10.4 & 8.7 & 8.9 & 5.5 & 9.4 & 12.1 & 1.0 & 13.6 & 9.3 & 5.7 & $\mathbf{0 . 8 1}$ & & \\
XIII & 19.2 & 11.2 & 7.9 & 8.4 & 6.7 & 10.3 & 12.2 & 2.6 & 13.2 & 9.4 & 6.0 & 1.9 & $\mathbf{0 . 0}$ & \\
XIV & 7.5 & 4.9 & 5.5 & 4.2 & 7.7 & 5.2 & 0.6 & 11.0 & 3.2 & 2.4 & 6.0 & 11.7 & 11.8 & $\mathbf{0 . 3 3}$ \\
XV & 11.7 & 3.4 & 5.5 & 4.5 & 3.1 & 2.7 & 4.9 & 6.7 & 7.4 & 2.5 & 2.1 & 7.5 & 8.0 & 4.7 & $\mathbf{0 . 6 8}$ \\
\hline
\end{tabular}

18 Ahmed et al 
distances indicating the presence of wider diversity among the germplasm of different clusters. However, the lowest intra-cluster distance were observed in clusters III and XIII as zero due to the presence of single genotype in both the clusters (TA15 and TA38 respectively), followed by cluster XIV (0.33) and cluster VIII (0.39) indicating the comparatively more homogenous in nature of the germplasm. The inter-cluster $\mathrm{D}^{2}$ values ranged from 19.2 to 0.6 indicating wide range of diversity. The highest inter-cluster distance was observed between clusters I and XIII (19.2) suggested wide diversity between these clusters, followed by between clusters I and XII (19.1), clusters I and VIII (18.3), clusters I and V (14.4) and clusters IX and XII (13.6). The lowest inter-cluster distance was observed between clusters VII and XIV (0.60), followed by clusters VI and X (2.55) and clusters II and VI (1.0) indicating the close relationship between the germplasm of these clusters and hence, may not be emphasized upon to be crossed each other in hybridization programmes. Hossain (2008) also reported intra- and inter-cluster distances ranged from 0.0 to 1.02 and 2.21 to 21.59 , respectively on aromatic and fine grain landraces of rice. However, germplasm belonging to these clusters may be further used in hybridization programme for the improvement of rice. Crosses involving parents belonging to the most divergent clusters would be expected to manifest maximum heterosis and wide variability of genetic architecture (Souroush $e t$ al., 2004).

Cluster means for the characters. Cluster XIII showed the highest leaf length $(82.2 \mathrm{~cm})$ and culm diameter $(6.5 \mathrm{~mm})$, cluster IX the highest number of effective tillers per hill (13), cluster II the lowest days to maturity (117), cluster XV the highest grain length $(6.1 \mathrm{~mm})$ and cluster I the highest grain LB ratio (2.97) respectively, while cluster VIII showed the highest yield per hill $(22.0 \mathrm{~g})$, panicle length $(28.8 \mathrm{~cm})$ and 1000 grain weight $(25.2 \mathrm{~g})$ (Table 7). As a result, the germplasm under cluster VIII may be selected for crossing with the germplasm from clusters XIII, IX, II, XV and I for developing high yielding T. Aman variety along with long panicle, high effective tiller numbers per hill, short growth duration and long-slender type grain. Islam et. al. (2017) earlier also reported the similar trend of conclusion using Mahalanobis' $\mathrm{D}^{2}$ statistic on rice.

Canonical variate analysis. In the present study, it also appeared from the canonical analysis that $52.51 \%$ of the total variation was accounted for canonical root 1 and $19.88 \%$ by canonical root 2 (Table 8).

Contribution of characters towards divergence. Table 9 presents the coefficients pertaining to the different characters in the first two canonical roots. The canonical variate analysis revealed that the grain LB ratio, culm diameter, effective tillers per hill, panicle length and days to maturity were positive for both the vectors (I and II) and were the most responsible for both the primary and secondary differentiations and contributed maximum to the genetic divergence. Such results indicated that these characters will offer a scope for selection of parents. Similarly, Islam et al. (2017) also found positive contribution of both canonical vectors for culm diameter, days to flowering, days to maturity and length-breadth ratio on Jhum rice landraces collected from Rangamati district in Bangladesh. 
Table 7. Cluster means of 54 T. Aman rice germplasm for 11 morphological and yield contributing characters.

\begin{tabular}{c|c|c|c|c|c|c|c|c|c|c|c}
\hline Cluster & $\begin{array}{c}\text { Leaf } \\
\text { length } \\
(\mathrm{cm})\end{array}$ & $\begin{array}{c}\text { Leaf } \\
\text { width } \\
(\mathrm{mm})\end{array}$ & $\begin{array}{c}\text { Culm } \\
\text { diameter } \\
(\mathrm{mm})\end{array}$ & $\begin{array}{c}\text { Effective } \\
\text { tillers } \\
\text { per hill }\end{array}$ & $\begin{array}{c}\text { Panicle } \\
\text { length } \\
(\mathrm{cm})\end{array}$ & $\begin{array}{c}\text { Plant } \\
\text { height } \\
(\mathrm{cm})\end{array}$ & $\begin{array}{c}\text { Day to } \\
\text { maturity }\end{array}$ & $\begin{array}{c}\text { Grain } \\
\text { length } \\
(\mathrm{mm})\end{array}$ & $\begin{array}{c}\text { Grain } \\
\text { LB } \\
\text { ratio }\end{array}$ & $\begin{array}{c}1000 \\
\text { grain } \\
\text { weight }(\mathrm{g})\end{array}$ & $\begin{array}{c}\text { Yield } \\
\text { per hill } \\
\text { (g) }\end{array}$ \\
\hline I & 46.8 & 11.7 & 4.2 & 10 & 23.7 & 88.1 & 119 & 5.9 & 2.97 & 17.3 & 6.4 \\
II & 47.1 & 13.8 & 5.3 & 8 & 23.7 & 132.7 & 117 & 5.7 & 2.17 & 22.3 & 6.37 \\
III & 33.0 & 11.0 & 5.1 & 11 & 24.4 & 154.4 & 139 & 4.1 & 2.10 & 9.5 & 6.3 \\
IV & 52.9 & 10.9 & 4.8 & 12 & 26.0 & 142.4 & 135 & 4.9 & 2.47 & 12.4 & 8.9 \\
V & 58.2 & 15.8 & 6.0 & 11 & 25.6 & 156.9 & 125 & 6.0 & 2.23 & 23.9 & 10.9 \\
VI & 55.9 & 14.9 & 5.2 & 10 & 21.9 & 135.6 & 121 & 5.6 & 2.14 & 21.3 & 6.33 \\
VII & 30.6 & 10.5 & 4.6 & 9 & 19.2 & 125.7 & 133 & 5.7 & 2.45 & 21.8 & 7.9 \\
VIII & 61.5 & 13.5 & 4.5 & 10 & 28.8 & 172.3 & 133 & 5.7 & 2.10 & 25.2 & 22.0 \\
IX & 44.5 & 11.2 & 5.0 & 13 & 23.6 & 122.6 & 135 & 4.6 & 2.36 & 11.1 & 8.4 \\
X & 62.3 & 12.7 & 6.2 & 11 & 23.7 & 130.7 & 133 & 5.8 & 2.40 & 20.7 & 13.0 \\
XI & 65.4 & 11.2 & 5.5 & 12 & 25.7 & 147.1 & 137 & 6.0 & 2.23 & 23.8 & 8.8 \\
XII & 49.5 & 11.7 & 5.3 & 11 & 25.3 & 182.9 & 133 & 5.5 & 2.25 & 16.0 & 6.4 \\
XIII & 82.2 & 11.0 & 6.5 & 8 & 27.2 & 167.8 & 143 & 5.3 & 2.10 & 22.7 & 12.7 \\
XIV & 47.0 & 12.4 & 4.5 & 10 & 23.0 & 120.7 & 142 & 5.9 & 2.20 & 25.1 & 15.6 \\
XV & 51.1 & 12.8 & 5.2 & 11 & 24.2 & 144.8 & 133 & 6.1 & 2.40 & 23.7 & 4.7 \\
\hline & & & & & & & & & & & \\
\end{tabular}

Table 8. Values of latent roots (canonical roots) and percentage of variation of 11 morphological characters of $54 \mathrm{~T}$. Aman rice germplasm.

\begin{tabular}{ccc}
\hline Canonical root & Value of the canonical root & $\begin{array}{c}\text { Percentage of variation absorbed by } \\
\text { the canonical root }\end{array}$ \\
\hline 1 & 24.54 & 52.51 \\
2 & 9.29 & 19.88 \\
3 & 6.35 & 13.59 \\
4 & 3.73 & 7.98 \\
5 & 1.22 & 2.60 \\
7 & 0.69 & 1.47 \\
8 & 0.37 & 0.79 \\
9 & 0.23 & 0.50 \\
10 & 0.17 & 0.35 \\
11 & 0.11 & 0.23 \\
Total & 0.04 & 0.09 \\
\hline
\end{tabular}


Table 9. Latent vectors for 11 morphological characters of 54 T. Aman rice germplasm.

\begin{tabular}{lccc}
\hline Character & Vector I & Vector II & Combined ranking* $^{*}$ \\
\hline Leaf length $(\mathrm{cm})$ & -0.0851 & -0.0104 & 8 \\
Leaf width $(\mathrm{mm})$ & 0.0851 & -0.2458 & 9 \\
Culm diameter $(\mathrm{mm})$ & 0.2782 & 0.4546 & 2 \\
Effective tillers per hill & 0.183 & 0.0856 & 3 \\
Panicle length (cm) & 0.0884 & 0.1272 & 4 \\
Plant height (cm) & -0.1961 & 0.0167 & 10 \\
Days to maturity & 0.0138 & 0.1515 & 5 \\
Grain length (mm) & -1.2476 & -2.1051 & 11 \\
Grain LB ratio & 1.8633 & 2.9192 & 1 \\
1000 grain weight $(\mathrm{g})$ & 0.0413 & -0.0153 & 7 \\
Yield per hill $(\mathrm{g})$ & -0.0121 & 0.0787 & 6 \\
\hline
\end{tabular}

*Combined ranking is estimated by summing the values of vector I and II, then higher (1) is the rank with higher positive value.

\section{CONCLUSIONS}

Since the modern variety with the narrow genetic base are vulnerable to diseases and adverse climatic changes, the genetically diverse genotypes for variety development become more important. Moreover, characterization of landraces could help to utilize appropriate characters in rice improvement programme. Indursail (TA30), Kartikjul (TA24), Kajal lata (TA3) and Subal lata (TA4) are the elite germplasm promising for one or more characters. Finally, the germplasm under clusters VIII may be selected for crossing with the germplasm from clusters XIII, IX, II, XV and I for developing high yielding variety along with long panicle, high effective tiller numbers per hill, short growth duration and long-slender type grain.

\section{REFERENCES}

Abarshahr, M, B Rabiei and H S Lahigi. 2011. Assessing genetic diversity of rice varieties under drought stress conditions. Notulae Scientia Biologicae 3(1): 114-123.

Bisne, R, N K Motiramani and A K Sarawgi. 2006. Association analysis and variability analysis in rice. Mysore J. Agric. Sci. 40 (3): 375-380.

Chakravorty, A, P D Ghosh and P K Sahu. 2013. Multivariate analysis of phenotypic diversity of landraces of rice of West Bengal. American J. Exp. Agric. 3(1): 110-23.

Chandra, R, S K Pradhan, S Singh, L K Bose and O N Singh. 2007. Maltivariate analysis in upland rice genotypes. World Journal of Agricultural Sciences 3(3): 295-300.

Das, S and A Ghosh. 2011. Characterization of rice germplasm of West Bengal. Oryza 47 (3): 201-205.

Goodman, M M. 1972. Distance analysis in biology. Syst Zool 21: 174-186.

Hasan, M J, M G Rasul, M A K Mian, M Hasanuzzaman and M M H Chowdhury. 2000. Genetic divergence of yam. Bangladesh Journal of Plant Breeding and Genetics 13(1): 07-11.

Hossain, M Z. 2008. Genetic diversity study in fine grain and aromatic landraces of rice (Oryza sativa L.) by morpho-physico-chemical characters and microsatellite DNA markers. PhD thesis, Department of Genetics and Plant Breeding, BSMRU, Gazipur, Bangladesh.

Iqbal, J, Z K Shinwari and M A Rabbani. 2014. Investigation of total seed storage proteins of Pakistani and Japanese maize (Zea mays L.) through SDS-PAGE markers. Pak. J. Bot. 46: 817-822.

Islam, M Z, M Khalequzzaman, M A Siddique, N Akter, M S Ahmed and M A Z Chowdhury. 2017. Phenotypic characterization of Jhum rice (Oryza sativa L.) landraces collected from Rangamati district in Bangladesh. Bangladesh Rice J. 21 (1): 47-57.

Kumbhar, S D, P L Kulwal, J V Patil, C D Sarawate, A P Gaikwad and A S Jadhav. 2015. Genetic diversity and population structure in landraces and improved rice varieties from India. Rice Sci. 22: 99-107.

Lahkar, L and B Tanti. 2017. Study of morphological diversity of traditional aromatic rice landraces (Oryza sativa L.) collected from Assam, India. Annals of Plant Sciences 6 (12): 1855-1861. 
Lin, M S. 1991. Genetic base of japonica rice varieties released in Taiwan. Euphytica 56: 43-46.

Mahalanobis, P C. 1936. On the generalized distance in statistics. Proc. Nat. Inst. Sci. India. 2: 49-55.

Mahalingam, A, R Saraswathi, J Ramalingam and T Jayaraj. 2012. Genetic studies on divergence and phenotypic characterization of indigenous and exotic indica germplasm lines in rice (Oryza sativa L.). African J. Agric. Res. 7 (20): 3120-28.

Maji, A T and A A Shaibu. 2012. Application of principal component analysis for rice germplasm characterization and evaluation. Journal of Plant Breeding and Crop Science 4 (6):87-93.

Pachauri, A K, A K Sarawgi, S Bhandarkar and G C Ojha. 2017a. Genetic variability and association study for yield contributing traits of promising core Rice germplasm accessions (Oryza sativa L.). Res. on Crops 18(1): 133-138.

Pachauri, A K, A K Sarawgi, S Bhandarkar and G C Ojha. 2017b. Agro-morphological characterization and morphological based genetic diversity analysis of Rice (Oryza sativa L.) germplasm. Journal of Pharmacognosy and Phytochemistry 6(6): 75-80.

Pervaiz, Z H, M A Rabbani, I Khaliq, S R Pearce and S A Malik. 2010. Genetic diversity associated with agronomic traits using microsatellite markers in Pakistani rice landraces. Electronic Journal of Biotechnology 13(3): 4-5.
Rao, C R. 1952. Advanced Statistical Methods in Biometric Research. John. Willey and Sons. New York.

Sajid, M, S A Khan, H Khurshid, J Iqbal, A Muhammad, N Saleem and S M A Shah. 2015. Characterization of Rice (Oryza sativa L.) germplasm through various Agro-morphological traits. Scientia Agriculturae 9(2): 83-88.

Sarawgi, A K and N K Rastogi. 2000. Genetic diversity in traditional aromatic rice accessions from Madhya Pradesh. Indian J. Plant Genet. Resour 13: 138-146.

Souroush, H R, M Mesbah, A Hossainzadeh and R Bozorgipour. 2004. Genetic and phenotypic variability and cluster analysis for quantitative and qualitative traits of rice. Seed and Plant Karaj 20: 167-182

Upadhyaya, H D, C L L Gowda and D V S S R Sastry. 2008. Plant genetic resources management: collection, characterization, conservation and utilization. Journal of SAT Agricultural Research 6: 1-16.

Xiyong, C, X Haixia, D Zhongdong, C Feng, Z Kehui and C Dangqun. 2012. Genetic evolution and utilization of wheat germplasm resources in Huanghuai winter wheat region of China. Pak. J. Bot. 44: 281-288.

Zhang, L N, G L Cao and L Z Han. 2013. Genetic diversity of rice landraces from lowland and upland accessions of China. Rice Sci. 20: 259-266. 